\title{
O DESPONTAR DA EDUCAÇÃo ESPECIAL NA ANPED ${ }^{1}$ SURFACING OF SPECIAL EDUCATION IN ANPED
}

\author{
Elcie F. Salzano MASINI²
}

\begin{abstract}
RESUMO: esta comunicação focaliza o nascimento do Grupo de Trabalho (GT) de Educação Especial na ANPEd. Constitui uma retomada histórica da proposta de um grupo de professores e pesquisadores, da área de Educação Especial, de diferentes universidades do Brasil, que discutiu a pertinência de constituir um GT de Educação Especial na ANPEd. Nesse sentido foi consolidado um calendário de encontros para discutir linhas de pesquisa e a legislação atinente à Educação Especial e encaminhado ofício à Diretoria da ANPEd requerendo, oficialmente, a abertura de um espaço para a Educação Especial nas Reuniões da ANPEd. Acompanhou o ofício a justificativa para tal solicitação, enfatizando que a inclusão da Educação Especial no âmbito do ensino superior, especificamente formação de professores em nível de graduação voltada para os vários aspectos de Educação Especial, fez surgir a necessidade de realização de pesquisas desenvolvidas e vinculadas a programas de pós-graduação em Educação. Em resposta à solicitação surgiu o Grupo de Estudos (GE) na ANPEd, em 1989. O artigo descreve o funcionamento do GE, da programação, dos participantes e de uma pesquisa coletiva envolvendo seis Estados do Brasil, que propiciou a passagem do GE a GT. A Educação Especial foi incluída como GT na XV Reunião da ANPEd, em 1992. São apresentadas decisões tomadas pelos participantes do GT, nessa Reunião, referentes aos objetivos e funcionamento do GT. No encerramento da XV Reunião da ANPEd, a primeira coordenadora do GT de Educação Especial - uma professora da Faculdade de Educação da USP, que coordenou o GT de Educação Especial, de 1989 a 1992 - passou a coordenação para uma professora da Faculdade de Educação da UERJ.
\end{abstract}

PALAVRAS-CHAVE: Educação Especial. Grupo de Estudos. Grupo de Trabalho. ANPd.

\begin{abstract}
This paper focuses on the creation of the Work Group (WG) of Special Education in ANPEd (National Association of Post-Graduation and Research). It is a historical review of a proposal made by a group of professors and researchers in Special Education from different Brazilian universities that discussed the importance of forming a WG of Special Education in ANPEd. A calendar of meetings that aimed the discussion of Special Education research and legislation was agreed, and an official letter requesting a special appointment for Special Education during ANPEd meetings was sent to their directors. The letter justified this request highlighting that the inclusion of the subject Special Education in the university curriculum, especially in undergraduate teaching courses, arose the need for developing research bound to Special Education graduate courses. As a result to that request, the Study Group (SG) was created in ANPEd in 1989. This article describes the functioning of the SG, the program, the participants and the cooperative research involving six Brazilian States, which moved the GS forward the WG. Special Education was included as a WG in the XV Annual Meeting of ANPEd in 1992. In that year the WG participants decided about the objectives and functioning of the WG. Upon the closing of the XV ANPEd Meeting, the first coordinator of the Special Education WG, a professor from the School of Education at the University of São Paulo, who coordinated the WG from 1989 until 1992, passed the coordination to a professor from the School of Education at Rio de Janeiro State University.
\end{abstract}

KEYWORDS: Special Education. Work Group. National Association of Post-Graduation and Research.

\footnotetext{
${ }^{1}$ Todos os dados apresentados neste artigo, inclusive folhas de frequência assinada pelos participantes nas reuniões do GE e do GT de Educação Especial, estão arquivados com a primeira coordenadora das atividades da Educação Especial na ANPEd. A terminologia utilizada neste artigo segue a adotada no período histórico focalizado, embora essa terminologia tenha, posteriormente, sido criticada e alterada.

${ }^{2}$ Universidade de São Paulo, Faculdade de Educação - delcie@uol.com.br
} 
MASINI, E. F. S.

\title{
A aurora da Educação Especial na ANPEd
}

Em decorrência do comunicado da Diretoria da ANPEd, sobre XII Reunião Anual, um grupo de professores, em 10 de maio de 1989, reuniu-se na Faculdade de Educação (FE) da USP, para discutir a pertinência de constituir um Grupo de Trabalho (GT) de Educação Especial na ANPEd. Foram decididas estratégias para constituição deste GT em duas frentes: 1) organização de um calendário de encontros para discutir linhas de pesquisa e a legislação atinente à Educação Especial; 2) encaminhamento de ofício à Diretoria da ANPEd requerendo, oficialmente, a abertura de um espaço, na XIII Reunião Anual da ANPEd, para ser debatido o assunto sob vários ângulos, tendo em vista a formação de um futuro GT.

A justificativa da constituição de um GT de Educação Especial, redigida por esse grupo de professores é apresentada a seguir.

\begin{abstract}
A inclusão da Educação Especial no âmbito do ensino superior, especificamente formação de professores e nível de graduação, fez surgir a necessidade de realização de pesquisas. Essas pesquisas têm sido desenvolvidas vinculadas a programas de pós-graduação em Educação, diretamente voltadas para os vários aspectos de Educação Especial.

Assim, hoje no Brasil, tanto em universidades particulares como públicas, tem se desenvolvido pesquisas nessas áreas, em nível de mestrado, doutorado ou ainda pós-doutorado. Tais razões, basicamente levaram este grupo de professores a propor a constituição de um GT específico de Educação Especial, no sentido de que o tema passe a ser contemplado nas reuniões anuais da ANPEd, de modo a ser discutido sob vários ângulos.
\end{abstract}

O ofício encaminhado à Diretoria da ANPEd foi assinado pelos seguintes professores presentes na reunião da FEUSP: Cecília Azevedo Lima Collares; Elcie F. Salzano Masini; Liliana Rochman Weller; Lucena Dall Alba; Maria de Lourdes Fagundes; Maria Luiza Sprovieri Ribeiro; Marcos José Silveira Mazzotta; Sahda Marta Ide; Shirley Silva; Tereza Nobuco Koseli.

O grupo indicou como coordenadora provisória do Grupo de Estudos de Educação Especial a professora Dra. Elcie F. Salzano Masini, da FEUSP.

Os encontros foram realizados conforme exposição a seguir.

A fim de manter presente a ideia central que motivou a formação do Grupo de Estudos, ou seja, a inclusão da Educação Especial como tema de um Grupo de Trabalho da ANPEd, são sintetizadas a seguir as informações e materiais referentes às reuniões ocorridas.

Em 18 de agosto de 1989, na FEUSP estiveram reunidos dez professores, pertencentes ao Instituto de Psicologia da USP, Faculdade de Medicina da USP e da UNICAMP, Faculdade de Educação da USP e duas alunas desta faculdade. A reunião se estendeu das 08:30 às 13:00 horas e focalizou, conforme previamente combinado, a questão da Legislação e Educação Especial. No período da manhã, o 
O despontar da Educação Especial

professor Marcos Mazzotta apresentou seu trabalho intitulado "Politica Nacional de Educação Especial", que serviu de pano de fundo para as discussões do grupo. O referido texto foi publicado no Caderno CEDES, n 23, da Editora Cortez de São Paulo.

Alguns dos professores participantes foram à Assembleia Legislativa do Estado de São Paulo, a fim de obter um exemplar do Anteprojeto da Constituição Paulista e das Emendas relativas ao Atendimento de portadores de deficiência e à Educação Especial. Esse material foi analisado e discutido pela Comissão de Educação Especial da FEUSP.

No dia 24 de novembro de 1989, o Grupo de Estudos de Educação Especial da ANPEd reuniu-se também na FEUSP, tendo como pauta prevista para a reunião a discussão sobre "Educação Especial na Lei de Diretrizes e Bases da Educação Nacional". Na ausência, todavia, dos colegas de outros Estados, os presentes entenderam ser apropriado o debate sobre a Constituição do Estado de Paulo, promulgada em 05/10/89. Assim sendo, foram discutidos o Capítulo III (Da Educação e Cultura e do Esporte e Lazer), o Capítulo VII (Da Proteção Especial) e a Seção I (Da Família, da Criança, do Adolescente, do Idoso e dos Portadores de Deficiência).

No dia 2 de outubro de 1990 foi realizada mais uma reunião na FEUSP, com a presença de colegas ligados à Universidade de São Paulo (Instituto de Psicologia, Faculdade de Medicina e Faculdade de Educação). Na referida reunião foram apresentados, conforme proposta aprovada na reunião anterior, esclarecimentos sobre as Pesquisas já desenvolvidas e em desenvolvimento na área de Educação especial, pelos presentes.

A fim de manter presente a ideia central que motivou a formação do Grupo de Estudos (GE), ou seja, a inclusão da Educação Especial como tema de um Grupo de Trabalho da ANPEd, são sintetizadas a seguir as informações e materiais referentes às reuniões ocorridas.

Em 18 de outubro de 1990, o Grupo de Estudos em Educação Especial, encaminhou à Diretoria da ANPEd informações e relatórios sobre os encontros realizados, além de dois outros comunicados, conforme segue.

\footnotetext{
- apresentação de trabalhos pelos componentes do Grupo de Estudos de Educação Especial no I Seminário Brasileiro de Pesquisa em Educação Especial, cujo tema central foi "Compromisso Sócio-político da Prática e Utilização da Pesquisa em Educação Especial", realizado na UFRJ, de 19 a 21/09/90.

- proposição, em Assembleia da XIII Reunião Anual da ANPEd, a continuação do Grupo de Estudos de Educação Especial, sob a coordenação da Profa. Dra. Elcie F. Salzano Masini, com o compromisso de incentivar a apresentação de estudos na área durante a próxima ANPEd.
}

Essa correspondência encaminhada à Diretoria da ANPEd foi assinada pelos seguintes professores presentes na reunião: Elcie F. Salzano Masini; Liliana 
MASINI, E. F. S.

Rochman Weller; Maria Amélia Almeida; Maria de Lourdes Fagundes; Maria Helena Nobre; Maria Luiza Sprovieri Ribeiro; Marcos José Silveira Mazzotta; Rosangela S. G Braga; Társia Regina da Silveira Dias; Vera Lúcia Barbosa.

\section{Grupo de Estudos de Educação Especial na XIV Reunião da ANPEd}

A primeira participação oficial do Grupo de Estudos de Educação Especial na Reunião da ANPEd contou com um número médio de 16 participantes, nos trabalhos apresentados.

Participaram das apresentações as seguintes Universidades e Instituições: Faculdade de Educação da USP; Pontifícia Universidade Católica de São Paulo; Secretaria de Educação do Maranhão; Universidade Estadual de Londrina; Universidade Estadual do Rio de Janeiro; Universidade Federal da Bahia; Universidade Federal Fluminense; Universidade de Santa Maria; Universidade Estadual de Campinas; Universidade Federal de São Carlos; UNESP de Marília.

As atividades do Grupo de Estudos objetivaram assegurar uma diretriz de ação junto à pessoa portadora de deficiência, assinalando a necessidade da profissionalização dos envolvidos em Educação Especial, em substituição ao trabalho comumente assistencial. Assim, a proposta que permeou as discussões deste Grupo de Estudos foi a ênfase na formação de professores (e outros profissionais) para atuarem com a pessoa portadora de deficiência na sua totalidade, e com a especificidade de sua deficiência.

Os participantes das sessões deste Grupo de Estudos pertenciam a diferentes Instituições Educacionais de várias cidades de sete Estados e trabalhavam e estavam envolvidos na área, quer em programas de pós-graduação, quer como professores, quer como alunos.

Ao longo de dois anos, desde 1989 quando a Educação Especial organizouse como Grupo de Estudos até a XIV Reunião da ANPEd, houve encontros de subgrupos com alguns desses participantes. Reunindo dados das discussões ocorridas nesse período, cujo teor se repetiu nas sessões da XIV Reunião da ANPEd, pode-se arrolar os temas de interesse reiterado, que requeriam atenção.

- No campo pedagógico, a falta profissionalismo - a proposta seria de substituir o cunho protecionista por um cunho educacional eficiente, preparando para uma função social produtiva.

- O serviço de atendimento aos deficientes, pelas Instituições requeria mudanças - em geral assistencialista, colocava o deficiente numa dívida de gratidão, preparando-o mal para utilizar os próprios recursos e na vida familiar, escolar e profissional e desenvolver-se.

Ficaram assinalados a falta de profissionais e o aumento da clientela de educação especial, apontando a necessidade de pensar em soluções alternativas para atender à demanda. Ficou enfatizado a importância do preparo adequado 
O despontar da Educação Especial

da pessoa deficiente, atendendo às suas necessidades especificas, com vistas à sua integração social e profissional.

Esses dados reiteraram a necessidade de aproximação e cooperação das Instituições envolvidas com a Educação Especial. As conclusões da XIV Reunião Anual, bem como a proposta de continuidade para a XV Reunião caminharam nesse sentido, como será exposto mais adiante.

\subsection{As sessões do Grupo de Estudos}

Dos 17 trabalhos provindos de diferentes cidades dos Estados do Paraná, Rio Grande do Sul, Rio de Janeiro e São Paulo foram selecionados oito para apresentação na XIV Reunião da ANPEd.

Os critérios utilizados para essa seleção foram estabelecidos pela Diretoria da ANPEd:

a) ter de 10 a 25 laudas;

b) ser em número suficiente para poder ser apresentado em três períodos (uma manhã e duas tardes).

c) ter semelhança de conteúdo com os agrupamentos feitos sob temas abrangentes.

d) aceitação de apenas uma produção do mesmo autor (ou autores).

A partir desses critérios os trabalhos selecionados ficaram reunidos sob três grandes temas:

- Aspectos referentes à Educação do Portador de Deficiência Mental.

- Atividades da vida diária do Portador de Deficiência Mental.

- Formação do professor de Educação Especial.

A distribuição dos temas, nas datas previstas, objetivou por em destaque a Formação de professores, tema escolhido para abrir os debates do Grupo de Estudos.

A programação ocorreu conforme segue.

1/9 - das 14:30 às 16:45h:

A Formação do Professor de Educação Especial.

- Mazotta, M.J.S. (FEUSP) - Tendências da formação de professores de Excepcionais

e sua correlação com as características da Educação Especial;

- Dias, Tárcia Regina S. e outros (UFSCar) - Um Programa de Pós-Graduação em Educação Especial: a Perspectiva.

- Masini, Elcie F. S. (FEUSP) - O Perceber e o Relacionar- se do D.V. - Orientando Professores Especializados.

1/9 - das 17:00 às 19:00h:

Levantamento de Questões Referentes a Formação de Profissionais de Educação Especial.

2/9 - das 08:30 às 10:45h: 
MASINI, E. F. S

Aspectos Referentes à Educação do Deficiente Mental.

- Jannuzzi, Gilberta (UNICAMP) - Oficina Abrigada e a "Integração do Deficiente Mental" - Um Estudo de Caso.

- Mantoan, M. Teresa E. (UNICAMP) - A Solicitação do Meio Escolar e o Desenvolvimento das Estruturas da Inteligência no Deficiente Mental.

- Ide, Sahda Marta (FEUSP) - A Alfabetização e a Deficiência Mental.

2/9 - das 11:00 às 12:00h:

Discussões sobre os GTs para Encaminhamento das Propostas.

2/9 - das 13:00 às 14:30h:

Atividades da Vida Diária do Deficiente Mental.

- Almeida, M. Amélia et al. (UEL) - A Atuação de Alunas do Magistério em Treinamento de AVD: Uma Análise Experimental.

- Reali, Aline M.M.R. (UFSCAR) - Uma Metodologia para a Observação do Comportamento de Alimentação Independente de Crianças Excepcionais.

2/9 - das 14:45 às 17:00h:

Conclusões, Avaliação e Encaminhamentos para Continuidade dos Trabalhos para a XV Reunião.

Foi prevista a seguinte distribuição de tempo para as exposições e debates de cada tema:

30 minutos para cada expositor.

10 minutos de debates sobre a exposição.

15 minutos apos as exposições e debates, para as conclusões.

Cada trabalho apresentado - pesquisa na área de Educação Especial exigiu do expositor esclarecimentos sobre sua fundamentação teórica e método de investigação. Foram apontados, quer pelo próprio pesquisador, quer pelos participantes, aspectos da fundamentação e metodologia que propiciaram ampliação de conhecimentos de novos aspectos da problemática investigada. Foram também levantados limites e lacunas para alcance dos objetivos propostos, sobre os quais foram levantados questionamentos importantes que levaram a debates bastante enriquecedores. São anotados a seguir alguns itens que foram mais discutidos.

- O uso do método fenomenológico em pesquisa junto ao portador de deficiência.

- Como conviveram as contradições teóricas num trabalho que se propunha fundamentar no Construtivismo, mas que utilizou classificações de deficiência mental definidas pelo Behaviorismo.

- No que e de que forma as pesquisas clínicas de registro de observação de comportamento podem trazer benefícios ao educador.

- Propriedade de instrumentos psicológicos utilizados em Pesquisas, para identificar portadores de deficiência mental.

- Alternativas ao uso de instrumentos para saber sobre o deficiente visual, frente a impropriedade de instrumentos utilizados nas Pesquisas para conhecer seu desenvolvimento cognitivo e social. 
O despontar da Educação Especial

\subsection{Avaliação - o Grupo de Estudos de Educação Especial na ANPEd}

A retaguarda da Diretoria da ANPEd para o desenvolvimento das atividades na XIV Reunião Anual foi sentida de diversas maneiras: através de orientações na fase preparatória; através das informações por escrito no decorrer dos trabalhos; abrigando o GE de Educação Especial, propiciando sua participação na Assembleia e aprovando no final da XIV Reunião Anual da ANPEd a transformação do Grupo de Estudos de Educação Especial para Grupo de Trabalho (GT). Esses foram elementos sem dúvida que contribuíram para os resultados que se pode atingir.

A utilização de uma sala de aula da FEUSP para as sessões do Grupo de Estudos foi satisfatória para o número de participantes. A solicitação de retroprojetor para as exposições foi prontamente atendida pelo serviço responsável, nos horários marcados.

Dois fatores pelo menos indicaram o grande interesse pelo Grupo de Estudos de Educação Especial:

- a produção científica na área, que se verificou pelo grande número, diversidade de temas e pesquisas sobre o assunto, enviados para a XIV Reunião Anual da ANPEd.

- a participação nas sessões do Grupo de Estudos, de Instituições variadas de diferentes cidades e Estados.

O ponto prioritário das discussões sobre os GT (segundo roteiro sugerido pela Diretoria da ANPEd) referiu-se à identidade do GT. No Grupo de Estudos de Educação Especial de Educação Especial, nesse sentido, chegou-se a seguinte definição que foi lida em Assembleia.

\footnotetext{
A Educação Especial tem sido objeto de grandes confusões.

Queremos deixar nosso repúdio público a interpretações equivocadas que identificam Educação Especial como instância simplesmente legitimadora das impropriedades do ensino regular.

Educação Especial não é um recurso remediativo para o fracasso escolar. Configura-se como um recurso educacional que assegura aos educandos com necessidades educacionais especiais o exercício do direito à Educação. Entende-se que tais educandos são os que por razões de ordem sensorial, mental ou física não se beneficiam das situações comuns de ensino.
}

\section{Planejamento do GT de Educação Especial Para o PRóximo Período}

No decorrer da XIV Reunião Anual, os debates sobre os trabalhos expostos, bem como sobre questões vivenciadas pelos participantes, levaram a definir prioridades de pesquisa e possibilidades de intercâmbio entre as Instituições envolvidas.

Foram assinalados os seguintes itens a serem considerados, para continuidade dos trabalhos do GT: 
MASINI, E. F. S.

- ênfase na instância educacional e não assistencial ou clínica;

- utilização de dados atualizados nas pesquisas a serem apresentadas (que se refiram a dados de no máximo tre anos a partir da conclusão da pesquisa);

- oportunidade para todas as áreas de Educação Especial (D.M. / D.V. / D.A. / D.F. / superdotados e problemas de conduta.

Para continuidade dos trabalhos, levando em consideração esses três itens, ficou estabelecida a seguinte Proposta de Pesquisa para os participantes do GT de Educação Especial da ANPEd:

1. O Registro por escrito da própria experiência.

Cada participante fará uma Descrição do que faz guiado pela seguinte questão: “Quais os projetos ou práticas, ou pesquisas, ou cursos, ou outras atividades que faz e como servem de subsídios à formação do educador ou pesquisador em Educação Especial?".

2. Envio dos registros para a Coordenadora do GT até 20/01/92 (3 cópias para serem encaminhadas a colegas do GT).

3. Análise dos dados registrados (mês de fevereiro).

Cabe à coordenadora:

a)estabelecimento dos critérios para análise.

b) distribuição entre os participantes do GT do material recebido, para que colaborem na análise.

4. Reunião dos participantes do GT (em 09/03/92).

Discussão sobre dados analisados.

Observação:

a) Solicita-se a confirmação da presença para organização da reunião.

b) Os que não puderem comparecer deverão enviar à Coordenadora do GT até 05/03/92 os dados analisados para que seja organizada a forma de trabalho da reunião de 09/03/92.

5. Organização da próxima etapa para redação das primeiras conclusões a serem apresentadas na XV Reunião Anual.

\subsection{SolicitaÇÃo PARA REALIZAÇÃo DA PRÓXIMA REUNIÃo}

Considerando que o desenvolvimento da referida Pesquisa seria um grande elo entre os participantes até a realização da próxima reunião, foi assinalado no relatório enviado à Diretoria da ANPEd, que esta demandaria um apoio efetivo da Diretoria da ANPEd no sentido de viabilizá-la. Tal apoio implicaria, necessariamente, a inclusão de recursos materiais e financeiros que oportunamente seriam apresentados pela coordenadora do GT de Educação Especial.

O Relatório da participação do Grupo de Estudos de Educação Especial, promovido a GT na XIV Reunião Anual da ANPEd, foi encaminhado à Diretoria da ANPEd no final de outubro. Em dezembro a Diretoria da ANPEd comunicou à coordenadora que o GT que a Pesquisa exploratória recebeu apoio da Diretoria da ANPEd no sentido de obtenção de financiamento de Órgãos Federais. Foi então realizada conjuntamente, por essa Diretoria e pela Coordenadora do GT, uma Proposta científica que viabilizasse a Pesquisa. Foi concedido apoio financeiro pela CAPES. 
O despontar da Educação Especial

\section{O INTERCÂMBIO DE PESQUISADORES}

A Coordenação recebeu relatos de 18 pesquisadores de 6 Estados (Bahia, Maranhão, Paraná, Pernambuco, Rio de Janeiro e São Paulo). Os pesquisadores (Aline M. de Rodrigues Reali - UFSCAR - São Carlos - SP; Carolina S. Itibere F. S. Silva - PUCSP - SP; Célia Maria Fernandes Nunes - UFSCAR - São Carlos - SP; Cláudia:Maria Lyra Pato - UnB - Brasília - DF; Elcie F Salzano Masini FEUSP - SP; Ester C. de Sousa Rosa - UFPE - Recife - PE; Gilberta Januzzi UNICAMP - Campinas - SP; Júlio Romero Ferreira - UNIMEP - Piracicaba - SP; Maria Amélia Almeida - UEL - Londrina - PR; Maria de Lourdes S. Fagundes UFF - RJ; Maria Teresa Mantoan - UNICAMP - Campinas - SP; Marcos J. Silveira Mazzotta - FEUSP - SP; Marília Alves Pedrosa Esau - PUCSP - SP; Marisa Ziglio - UFRGS - Passo Fundo - RGS; Paula. F. da Silva Sousa - Secr. Educação. - S Luís - MA; Sahda Marta lde - FEUSP - SP; Sandra M Lima Sousa - FEUSP - SP; Shirley Silva - UNICAMP - SP) que enviaram a descrição de suas atividades foram assim caracterizados, no que diz respeito ao envolvimento com programas de Pós Graduação:

Prof. Dr. Orientador de Mestrado e Doutorado 2

Prof. Dr. Orientador de Mestrado

2
7

Prof. Mestre Orientador de Monografias e Projetos em Cursos de

Especialização $\quad 5$

Mestrandas que desenvolvem suas pesquisas em Educação Especial 4

Estiveram presentes no Intercâmbio 12 pesquisadores, ficando ausentes: a representante do Estado do Maranhão, uma pesquisadora do Rio de Janeiro e quatro pesquisadoras do Estado de São Paulo.

O objetivo do intercâmbio foi de reunir Instituições e pessoas para sistematizar o registro de atividades em Educação Especial. Visou desenvolver análise do material de diferentes regiões do país para traçar um perfil do trabalho nessa área, naquilo que tem contribuído para a formação do professor especializado e do pesquisador. Delineou-se, assim, uma forma de trabalho para viabilização da pesquisa denominada "Perfil, do que está sendo feito em Educação Especial, por um grupo de educadores pesquisadores".

O registro por escrito de ações heterogêneas e autônomas e, sobretudo, o delineamento do que sucedia na área, a partir de diversas experiências, não foi fácil. Requereu um caminho próprio de análise e interpretação dos dados. Exigiu clareza na fundamentação teórica e estabelecimento de um método de pesquisa para análise do material escrito. Fez-se imprescindível, para viabilização dessa proposta, um encontro dos participantes e o estabelecimento de diretrizes teóricas e metodológicas para análise dos dados registrados. Foram, dessa forma, estabelecidas e realizadas, nessa reunião de intercâmbio, as seguintes etapas: 
MASINI, E. F. S.

1. Relato por escrito das atividades desenvolvidas em Educação Especial, enviado à coordenadora do GT de outubro de 1991 a janeiro de 1992. Esse material foi distribuído a cada um dos participantes da reunião de intercâmbio.

2. Análise do material escrito, realizado em dois momentos:

a) organização do material pela coordenadora e estabelecimento das diretrizes de análise - janeiro a abril de 1992;

b) sistematização do material pelo grupo de participantes presentes na reunião de intercâmbio, por meio de descrição e interpretação dos dados e redação das conclusões.

A pauta para viabilização dessa sistematização do material, análise e conclusões foi a que segue.

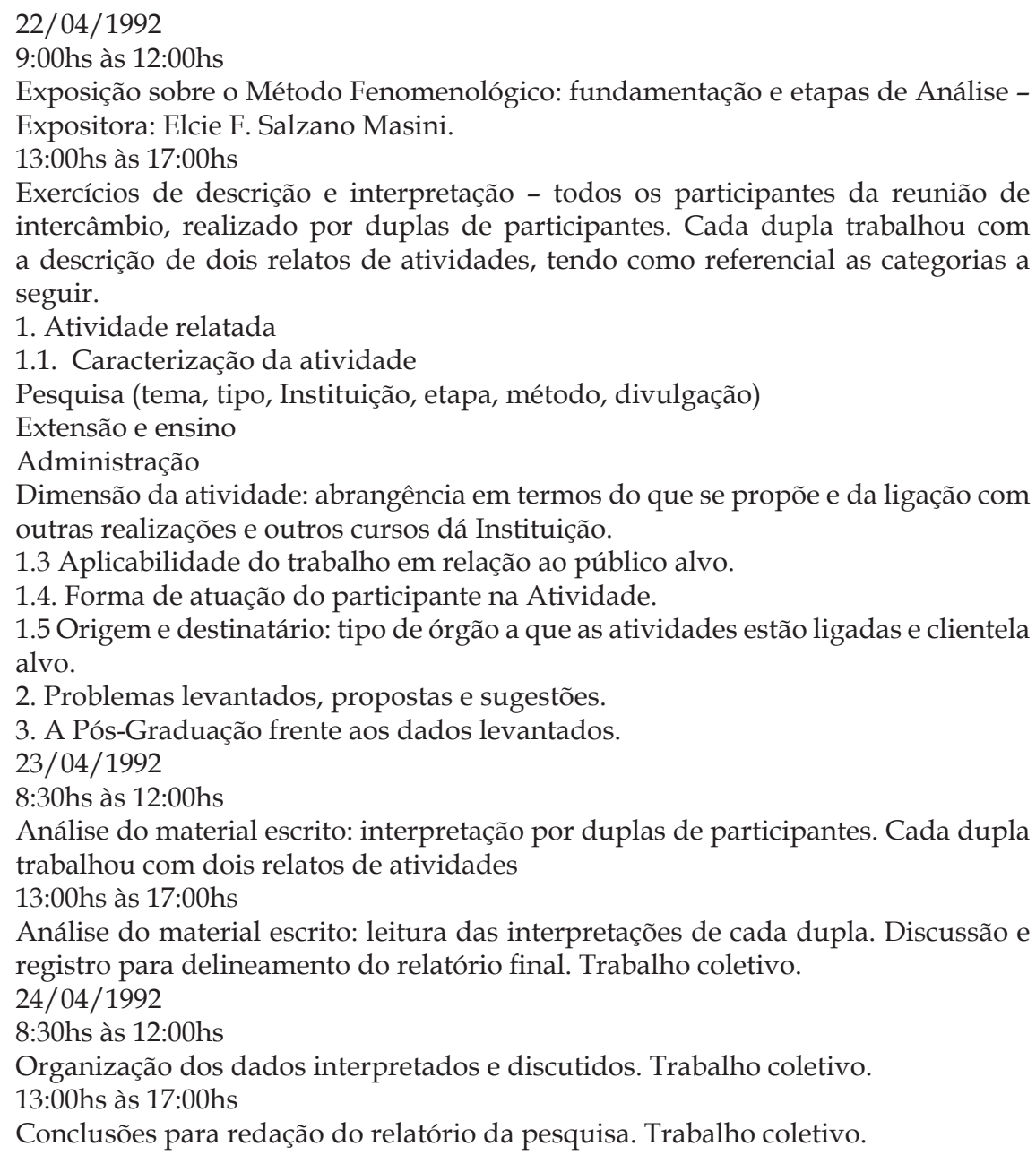

O relatório final da pesquisa foi realizado pela coordenadora do GT para ser apresentado na XV Reunião Anual da ANPEd. 
O despontar da Educação Especial

\section{O GT de Educação Especial na XV Reunião Anual da ANPEd}

Coordenadora: Elcie F. Salzano Masini

Número médio de participantes: 15

Universidades e Instituições representadas: FUA (Amazonas); INCOR (Caxambu); UEL (Londrina); UERJ (Rio de Janeiro); UFES (Espírito Santo); UFPE (Pernambuco); UFV (Viçosa); UFSM (Santa Maria-RS); USP (São Paulo).

A sessão de Trabalhos Encomendados contou com as comunicações escritas da Profa. Dra. Társia Dias, da UFSCar e do Prof. Dr. Marcos Mazzotta, da FEUSP, sobre o tema: "Formação do Educador e do pesquisador em Educação Especial", tema definido pelo GT para essa Reunião Anual. Ambos não puderam estar presentes.

Os participantes do GT ao optarem na XIV Reunião Anual, por uma pesquisa conjunta, abriram mão da apresentação de trabalhos individuais. Assim só constam na "Sessão de Trabalhos Apresentados", aqueles que tratam de temas diferentes do definido pelo GT. Para essa Sessão foram selecionadas as pesquisas da Profa. Dra. Maria Teresa Mantoan, da UNICAMP e da Profa. Ângela Camacho da Silva, da UFRJ.

Essa decisão dos participantes do GT, bem como o apoio da Diretoria da ANPEd (proporcionando o Intercâmbio), não foi devidamente contemplada nos horários previstos para as comunicações e atividades do GT na XV Reunião Anual. A Diretoria reservou para a pesquisa conjunta apenas um período. A maior parte do tempo do GT foi dedicado à Pesquisa exploratória, cujos dados foram expostos pela coordenadora do GT, do qual são apresentados a seguir os itens mais relevantes.

A delimitação da área de Educação Especial do GT, levou em consideração as dúvidas surgidas quanto a algumas atividades registradas nos relatos apresentados na reunião do intercâmbio na etapa de organização da pesquisa exploratória "Perfil do que um Grupo de Educadores de 6 Estados faz em Educação Especial". Decidiu-se, por consenso, as temáticas que deveriam ser listadas e reconhecidas como incluídas na área do GT. Algumas atividades relatadas, dessa forma, não apareceram no relato da pesquisa, dentre as quais "Meninos de rua" e "problemas de conduta", por suscitarem a necessidade de serem definidas com maior precisão, ao nível do GT, na ótica de Educação Especial.

Constatou-se que as Pesquisas em geral estão voltadas para o portador de Deficiência Mental.

Referente à formação do educador, a análise dos relatos mostrou que nem todas as Universidades têm Habilitação no Curso de Pedagogia para formação do professor especializado, como se pode ver nos dados apresentados a seguir: 
MASINI, E. F. S.

\begin{tabular}{|ll}
\hline Universidades e Habilitação para formação do \\
\hline Há Habilitação & Não há Habilitação \\
USP & UFF \\
UERJ & UFSCar \\
UNICAMP & UFB \\
UNIMEP & UEL \\
& UEPe
\end{tabular}

Quadro 1 - Universidades e Habilitação para formação do Professor Especializado

Esse quadro desencadeou as questões apresentadas a seguir, que foram discutidas na XV Reunião da ANPEd e ficaram como sugestão para os participantes levarem como tema para debate em suas Universidades.

1. Como é formado o professor especializado?

2. Que estrutura tem a Universidade para formação do professor nesta área?

3. Que informações e instrumentação tem o professor do ensino regular para o encaminhamento do aluno especial?

4. Que abordagem política e ideológica os cursos de formação do educador tem para lidar com a Educação Especial?

5. A quem cabe a responsabilidade da formação de atendentes ou outros profissionais que trabalham com deficientes, inclusive pais?

Duas questões básicas permearam a discussão a respeito da pós- graduação frente aos dados levantados:

1. Até que ponto as Pesquisas, desenvolvidas em cursos de pós-graduação, atendem às necessidades da prática? Há integração sobre o que se pesquisa e o que se precisa saber para uma atuação no campo educacional?

2. Os relatos não trouxeram referências à divulgação do saber cientifico, desenvolvido pelos pesquisadores. Sem divulgação não há conhecimento.

Esses dois itens alertaram para a necessidade de um órgão divulgador do que se realiza em Educação Especial.

Ficaram como pontos de preocupação no final da análise a serem discutidos pelo GT de Educação Especial, na XV Reunião e em outros momentos:

1. Definição de linhas de pesquisa prioritária frente aos problemas levantados em Educação Especial, buscando solucioná-los. 
O despontar da Educação Especial

2. Ênfase do GT como canal de ligação entre a prática registrada nos relatos e nas demais comunicações a serem feitas, e a importância da Pós-graduação (dos orientadores e pesquisadores envolvidos) para fundamentar e assessorar a prática.

Surgiu ainda a questão dos Cursos de Pós-graduação lato sensu, tendo sido apontada a necessidade de se reestudar a política quanto aos critérios de lato sensu, à carga horária e monografias, ao nível de Conselho Federal de Educação e CAPES.

Quanto às questões referentes à formação do professor especializado e a Universidade, as discussões baseadas nos Trabalhos Encomendados para o GT de Educação Especial, assinalaram dois pontos básicos:

1. A importância da formação de um educador que disponha de ampla fundamentação em Educação.

2. A necessidade de Cursos, que ofereçam recursos práticos e conhecimentos teóricos, para o trabalho especifico com o portador de deficiência.

Os participantes organizaram-se para dar continuidade a essa Proposta, reunindo-se em horários extras, merecendo destaque os seguintes aspectos propostos, para ampliação de conhecimentos do tema do GT:

1. Ampliação da Pesquisa para âmbito nacional e aprofundamento, no que diz respeito às tendências metodológicas e teóricas.

2. Concentração de esforços, integrando os Seminários de Pesquisa no GT de Educação Especial.

Decisões tomadas junto aos participantes do GT.

Elcie F. Salzano Masini, considerando cumprida sua função de fortalecimento da Educação Especial junto à ANPEd, como coordenadora do Grupo de Estudos e do GT de Educação Especial, propôs que outro colega assumisse essa coordenação.

Ficou decidido que coordenação do GT, deveria ser renovada de dois em dois anos e deveria passar por vários Estados. A Educação Especial iniciou suas atividades na ANPEd como Grupo de Estudos (GE) na XII Reunião Anual em 1989, passando a Grupo de Trabalho (GT) em 1991. Desde seu aparecimento até a XV Reunião a coordenação esteve junto à Faculdade de Educação da USP, passando no final da XV Reunião da ANPEd para a Faculdade de Educação da UERJ.

A definição sobre a identidade do GT, feita na XIV Reunião da ANPEd, foi rediscutida na XV. Ficou então estabelecido o que segue: Educação Especial diz respeito ao atendimento educacional de alunos com necessidades especiais, portadores de DA / DF / DM / DV / Superdotados / Múltipla deficiência / problemas de conduta, excetuando meninos de rua. Ficou para ser rediscutido 
MASINI, E. F. S.

na XVI Reunião se alunos com problemas de aprendizagem e de psicose seriam incluídos ou não nessa definição.

Os Seminários de Pesquisa em Educação Especial, iniciativa de alguns pesquisadores da UERJ e UFRJ, depois integrado por outras Universidades, passaram a partir da XV Reunião da ANPEd a ser assumido pelo GT de Educação Especial. Ficou estabelecido que Seminário de pesquisa (39) ocorreria em junho de 1993, tendo uma dupla coordenação: a atual coordenadora e a ex-coordenadora do GT em Educação Especial, respectivamente, Maria Cecília de Freitas Cardoso e Elcie F. Salzano Masini.

\section{REFERÊNCIAS}

MAZZOTA, M. J. S Política Nacional de Educação Especial, Campinas, Caderno CEDES, n.23, p.5-15, 1989.

SÃO PAULO (Estado). Constituição do Estado de São Paulo. Promulgada em 5 de outubro de 1989. 